\title{
Satellite Image Processing for Land Use and Land Cover Mapping
}

\author{
Ashoka Vanjare $^{1+}$, S.N. Omkar ${ }^{1 *}$, J.Senthilnath ${ }^{1}$ \\ ${ }^{1}$ Department of Aerospace Engineering, Indian Institute of Science, Bangalore \\ Corresponding Authors Email: +ashokavanjare@gmail.com, *omkar@aero.iisc.ernet.in
}

\begin{abstract}
In this paper, urban growth of Bangalore region is analyzed and discussed by using multi-temporal and multi-spectral Landsat satellite images. Urban growth analysis helps in understanding the change detection of Bangalore region. The change detection is studied over a period of 39 years and the region of interest covers an area of $2182 \mathrm{~km}^{2}$. The main cause for urban growth is the increase in population. In India, rapid urbanization is witnessed due to an increase in the population, continuous development has affected the existence of natural resources. Therefore observing and monitoring the natural resources (land use) plays an important role. To analyze changed detection, researcher's use remote sensing data. Continuous use of remote sensing data helps researchers to analyze the change detection. The main objective of this study is to monitor land cover changes of Bangalore district which covers rural and urban regions using multi-temporal and multi-sensor Landsat - multi-spectral scanner (MSS), thematic mapper (TM), Enhanced Thematic mapper plus (ETM+) MSS, TM and ETM+ images captured in the years 1973, 1992, 1999, 2002, 2005, 2008 and 2011. Temporal changes were determined by using maximum likelihood classification method. The classification results contain four land cover classes namely, built-up, vegetation, water and barren land. The results indicate that the region is densely developed which has resulted in decrease of water and vegetation regions. The continuous transformation of barren land to built-up region has affected water and vegetation regions. Generally, from 1973 to 2011 the percentage of urban region has increased from $4.6 \%$ to $25.43 \%$, mainly due to urbanization.
\end{abstract}

Index Terms - Urban growth analysis, Land use, Land cover, Change detection, Multi-temporal satellite images.

\section{INTRODUCTION}

Multi-temporal satellite images provide an excellent spatial temporal features [1] and it is also freely available in the public domains [2]. Multi-temporal satellite images [3] are widely used in applications for studying both long term and short term change detection. Some of the applications in change detection - in case of short term change detection are crop yield estimation [4] and flood assessment [5], and in case of long term temporal change detection are fuel type assessment [6], and urban growth analysis [7-9] were studied.

In this paper, urban growth analysis of Bangalore region is analyzed by using multi-temporal satellite images. Increasing population has resulted in rapid urbanization. This has led to an increase in the need for infrastructure development which in turn has resulted in traffic congestion and basic amenities [2]. Hence demand for infrastructure has resulted in exploitation of naturalresources. The continuous exploitation of natural resources has led the researchers to study significant change detection caused by human impact.

The monitoring of land use and land cover (LULC) is carried-out by using remote sensing data which involves the use of several multi-date and multi-sensor satellite images [10-12]. The successful uses of remote sensing data are obtained by having an adequate understanding of landscape features [13] and imaging systems [14]. Satellite data are the most common data sources for studying change detection [15] and region mapping [13]. It is used because of its repetitive data acquisition, data storage, digital processing [14] and analyzed the content.

In literature, change detection techniques [16] and classification accuracy methods [13-16] have been devised by researchers to study LULC mapping problems. Urban settlements are common in all parts of the world and it is growing at a very high pace. In India, cities such as Delhi, Mumbai, Calcutta, Chennai and Bangalore are witnessing a significant urban growth due to improper urban planning. In these urban regions, Bangalore region is widely affected due to rapid industrialization. The city is witnessing exploitation of natural resources [17] in terms of decrease in number of wetlands and also decrease in rainwater catchment areas. So these factors have lead researchers to use multi-temporal satellite images in order to study the significant changes that have occurred due to human activities.

Researchers have used supervised and unsupervised techniques [18-21] to classify satellite images [9-12]. Image classification is a technique to categorize all the image pixels into group of similar classes. Remote sensing data are used to perform classification which is based on the spectral patterns. The objective of image classification [22-29] is to identify the unique features occurring in an image that actually represent on the ground features. Bakr et al. [1] used multi-temporal Landsat data for observing land cover changes. In their study, they have used maximum likelihood and Iterative 
self-organizing maps methods to classify satellite images. Dengsheng $\mathrm{Lu}$ et al. [12] successfully used Landsat images for studying impervious surface change detection in urban-rural frontier using supervised linear spectral mixture analysis method. Anderson et al. [10] has proposed different levels (single and multi-level) of classification system for LULC mapping problems. Dengsheng et al. [12] successfully used linear spectral mixture analysis in order to detect impervious surface in urban-rural frontiers. Javed Mallick et al. [21] estimated land surface temperature from Landsat-7 ETM+ images using maximum likelihood classification and minimum noise fraction methods for classifying satellite images. El-Kawya et al. [22] made use of image enhancement and visual interpretation techniques in order to improve supervised classification on Landsat images. CampsValls et al. [23] designed a framework for supervised method using support vector machine based on kernels for multi-temporal and multi-source remote sensing data classification. Esch $\mathrm{T}$ et al. [24] have used satellite images for determining impervious surface using support vector machines algorithm. Weber $\mathrm{C}$ et al. [25] have used a stepwise discriminate analysis, a supervised method for land cover classification. Avic et al. [26] presented hierarchical classification method to classify Landsat TM imagery in order to map land cover regions.

Ramachandra T.V et al. [2] have used Landsat images of greater Bangalore district with an approximate area [27] of $61 \mathrm{~km}^{2}$ for studying urban growth. In their study, they have used bayesian networks to classify the images and observed significant decrease in the number of water bodies. In our study, we are considering an area of 2182 $\mathrm{Km}^{2}$ for analysis of Bangalore urban growth. Here, we have used different satellite sensors like LANDSAT MSS, TM, and ETM+ sensor images for studying Bangalore urban growth. The multi-temporal satellite images with a period of 39 years are used for this study.

Initially, the images are pre-processed [30-59] using different image processing techniques for analysis of land cover regions. These images are classified using maximum likelihood classification method to produce thematic map into four classes - built-up, vegetation, water and barren lands. Thematic classification results assist researchers in determining the number of pixels of each region for studying the change detection. The main objectives of this study are: 1) to provide a recent perspective for different land cover types of Bangalore region, and 2) monitoring land cover changes of Bangalore region from the year 1973 to 2011 by using maximum likelihood classification technique.

This paper is divided into following sections, section 2 details data preparation technique, image classification techniques are given in section 3 , results and discussions are given in section 4 and section 5 presents the conclusions.

\section{DATA PREPARATION}

In this section, the image pre-processing methods are discussed. Initially, this pre-processing stage is used to improve the image quality. The main steps in preprocessing [1-12] involve resampling, geo-referencing, sub-setting and cloud removal [28-35]. All satellite images are geo-referenced using known ground control points (GCP's) and the given datasets are projected to world geodetic system (WGS) - 84 (Zone-UTM 43 North) as the datum. Landsat ETM+ experienced a failure of its Scan Line Correcting (SLC) on May, 2003 and it showed permanent disability in SLC. In LANDSAT ETM+ images, gap filling [31-32] is carried out by copying adjacent pixels for correcting SLC method. Filling the scan gap requires precise knowledge, so adjacent pixels are copied into missing pixels. The resultant of gap filling is shown in the Fig.1.
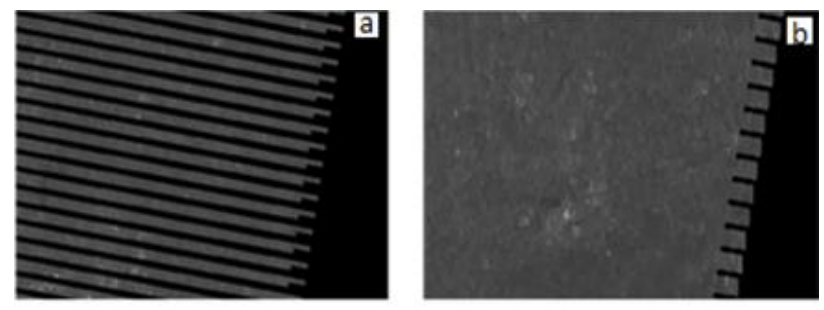

Fig 1: (a) Satellite image of Landsat 7 showing before scan line corrector failure and (b) Satellite image of Landsat 7 showing after scan line corrector failure.

In this paper, three different sensors, namely, multispectral scanner (MSS), thematic mapper (TM), Enhanced Thematic mapper plus (ETM+) are used for studying change detection for Bangalore region. Here, except thermal band we have used all the multi-spectral bands of 1973, 1992, 1999, 2002, 2005, 2008, 2010 and 2011 for classification. The different satellite sensors are used in this paper are given below:

1) Landsat MSS with 4 bands and 79 mtrs resolution acquired on $27^{\text {th }}$ Feb 1973.

2) Landsat TM with 7 bands and 30 mtrs resolution acquired on 14th Jan 1992

3) Landsat TM with 7 bands and 30 mtrs resolution acquired on 7th April 1999.

4) Landsat ETM+ with 8 bands and 30 mtrs resolution acquired on 18th Feb 2002.

5) Landsat ETM+ with 8 bands and 30 mtrs resolution acquired on 25th Jan 2005.

6) Landsat ETM+ with 8 bands and 30 mtrs resolution acquired on 18th Jan 2008.

7) Landsat ETM+ with 8 bands and 30 mtrs resolution acquired on 23rd Jan 2010.

8) Landsat ETM+ with 8 bands and 30 mtrs resolution acquired on 31st March 2011.

\section{A. Resampling}

Initially all the given satellite images are re-sampled [33]. This is a process in which all the different images of different resolution are converted into a standard resolution [1]. In re-sampling, the root means square error (RMSE) is reported to be less than 0.3 pixels. RMSE value between any two different dates and different sensor is acceptable if it is less than 0.5 pixels. 
The RMSE error value after re-sampling for the data used in this study is 0.3 pixels which is less than 0.5 pixels. So this data set can be used for classification.

\section{B. Geo-correction}

Landsat datasets are geo-corrected with known ground control points (GCP). For geometric correction we have considered 2011 satellite image as reference images where all other images used in this work are re-sampled and co-registered to the reference image. Geo-correction is done using both topo-maps and ground control points (GCP). Each satellite images are geo-referenced by keeping 100 GCP (ground control points) for all the images (1973-2011).

\section{Subsetting region of interest}

Survey of India top sheets of 1:50,000 and 1:2, 50,000 scales [35-38] were used to generate vector layer (base layer). The vector layer is prepared by digitizing the administration boundary and it is overlaid on raster layers (satellite images). Here the geo-referenced data (both raster image and vector layers) are used to subset the region of interest. In the Fig. 2, region of interest is cropped from given satellite image (full swath).

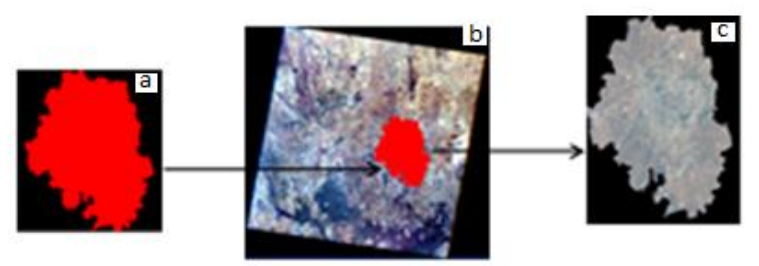

Fig 2: (a) Shape File of Bangalore, (b) Bangalore Shape File overlaid on the Original Image, (c) Bangalore district is cropped from Original Image

\section{Cloud Removal}

Generally, in multi-spectral imaging, fusion techniques are used to remove cloud pixels from the satellite images by replacing each pixels of the main image by using a reference image. For LANDSAT ETM+ 2011 image, the isolated cloud pixels were found by visual inspection. So we used image fusion method for removing cloud pixels [30-39]. Image fusion method is a process of combining information from two or more images in order to create another image [13-15]. The six bands of Landsat ETM+ 2010 nearest date image are used for replacing Landsat ETM+ 2011 image for cloud pixel replacing. For each band, we have corrected the brightness and a threshold is used for detecting the cloud pixels. The different solar irradiance and atmospheric effects are eliminated from each spectral band by assuming linear relation [29-32] between the corresponding brightness values of the two images.

The equation which is used for brightness correction is given by,

$$
f_{r e f}^{\prime}(i, j)=\frac{\sigma_{\text {main }}}{\sigma_{r e f}}\left[f_{r e f}(i, j)-m_{r e f}\right]+m_{\text {main }}
$$

where $f^{\prime}{ }_{r e f}$ is the new value, $f_{\text {ref }}$ is the brightness value of a pixel of the reference image, $m_{r e f}$ is the mean of the reference image, $\sigma_{r e f}$ is the standard deviation of the reference image, $m_{\text {main }}$ is the mean of the clouded image and $\sigma_{\text {main }}$ is the standard deviation of the clouded image. Here the clouded image is considered to be an original image which is adjusted using the reference image. So that, it's mean and standard deviation match the clouded image. Clouds reflect [30] the solar radiation in the visible and infrared spectra to a much higher degree than open grounds so we set a threshold $C_{1}\left(C_{1}=250\right)$ to distinguish between cloud regions and the open ground regions (where open ground region pixel value is nearly 150). The value of the threshold $\mathrm{C}_{1}$ is determined by histogram values of the image. Further, we compute absolute value in order to determine the reliable detection (i.e. difference between the same locations of the main image and the brightness-corrected reference image) is given by,

$$
f_{\text {main }}(i, j)>c_{1} \cup f_{r_{\text {ref }}}^{\prime}(i, j)>c_{1} \cap\left|f_{\text {main }}(i, j)-f_{\text {ref }}^{\prime}(i, j)\right|>c_{2}
$$

where $f^{\prime}{ }_{r e f}$ is the reference image, $f_{\text {main }}$ is the main image, $m_{r e f}$ is the mean of the reference image, $\sigma_{r e f}$ is the standard deviation of the reference image, $m_{\text {main }}$ is the mean of the main image and $\sigma_{\text {main }}$ is the standard deviation of the main image $A$ threshold $C_{2}\left(C_{2}=200\right)$ is used to ensure the reliability and validation of the detected region in clouded region. A binary decision map is generated by using two thresholds values $C_{1}$ and $C_{2}$. To identify cloud shadow pixels in case of satellite bandsgray format is very hard (due to brightness value of shadow is quite close to other regions and it is much smoother than the other those of the other surrounding regions). The cloud-free pixels from 2010 image information are used to replace 2011 image clouded pixels. After all the pre-processing steps the final data sets are shown in the Fig.3. From the Fig.3, we can make out visually all the clouded pixels are removed.

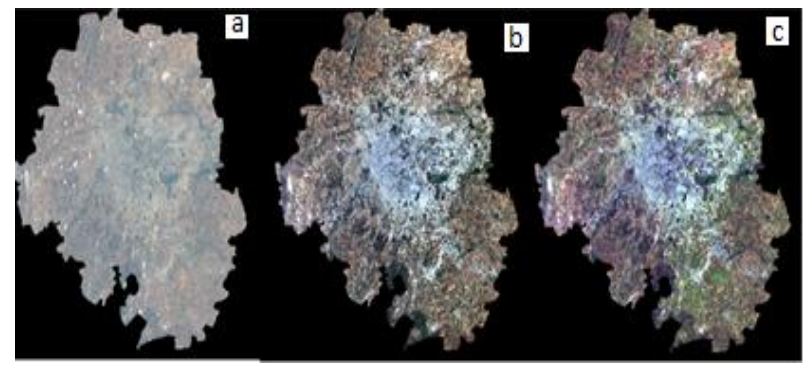

Fig 3: (a) Clouded image of Landsat ETM+ 2011, (b) Cloud free image of Landsat ETM+2010, (c) Clouded image pixels replaced in Landsat $\mathrm{ETM}+2011$ 


\section{IMAGE ClASSIFICATION METHOD}

Image classification methods [36-40] are very useful in identifying different features from the given image. Features like built-up, water, vegetation and barren land can be used for exploring in order to understand the multi-temporal variations. Multi-temporal satellite images [6-12] provide excellent temporal variations which can be used for urban growth analysis. Different combinations of bands [13-15] are generated in order to identify built-up, vegetation, water and barren land signatures from the satellite images (signatures means similar spectral values). The supervised classification methods are used for pattern classification [16]. Supervised classification [16] identifies class information in the satellite images and similar pixels are used as 'training samples' (signature values). The classifier system is used to determine the statistical characterization of reflectance for each information class and this stage is called 'Signature analyses'. Signature analyses involve statistical characterization of the range of reflectance on each band. The statistical characterization has been achieved for each information class. Then the image is classified by examining the reflectance for each pixel and making a decision about which of the signature it resembles accurately [13-18].

The band combinations for each image are shown below which are used to collect signatures or training samples from the given datasets:

1) Landsat-MSS 1973 data with band combinations (for false color composite (FCC) - 321 band and True color composite (TCC) - 432 band)

2) Landsat-TM 1992, 1999 data with band combinations (for FCC - 432 band and TCC 321 band)

3) Landsat-ETM+ 2002, 2005, 2008, 2011 data with band combinations (for FCC 432 band and TCC 321 band)

In Fig.4, the band combinations are used for collecting training samples. The collected samples are given as input to maximum likelihood classification method. Satellite image are classified using ERDAS® - classifier module. Maximum Likelihood Classifier (MLC) is a well-known parametric statistical classifier algorithm [16]. In MLC, normal distribution is assumed for the input data. The input data consists of two parameters - a mean vectors and a covariance matrix for estimation of class distributions. The mean and covariance matrix is used in discriminant functions to find discrimination in the distribution. The discriminant function in MLC is given by:

$$
g_{i}(x)=-\ln \left|\sum_{i}\right|-\left(X-m_{i}\right)^{T} \sum_{i}^{-1}\left(X-m_{i}\right)
$$

where $X$ is the $m$ dimensional input feature vector, $m_{i}$ is the mean feature vector for class $i, \Sigma_{i}$ is the covariance matrix for each class $i$ with the size of $m^{*} m$ and $n$ is the number of classes. MLC [16] is considered as standard classification algorithm for comparing with the other algorithms. The samples are represented by cluster space representation where information (or samples) is automatically assigned to their spectral classes. Pixel labelling is carried-out by combined decision based on its relationship to the defined clusters and cluster membership of the belonging information classes. The accuracy assessment is carried-out using known ground control points (GCP's) and for cross verifying we have used Google Earth ${ }^{\circledR}$ tool. Google Earth data (http://earth.google.com) is used for pre-classification and post-classification processes and validation of the results. The results are compared and analyzed using classification matrix.

\section{RESUltS AND DisCUSSIONS}

In this section, descriptions of the study area and land cover change analysis are discussed. The Study areaBangalore region is located in the south of Karnataka state. It is the capital city of Karnataka state. It is India's third most populous city and also it is fifth most populous urban agglomeration. The latitude and longitude of central Bangalore region is $12^{\circ} 58^{\prime} 0^{\prime \prime} \mathrm{N}$ and $77^{\circ} 34^{\prime} 0^{\prime \prime} \mathrm{E}$.

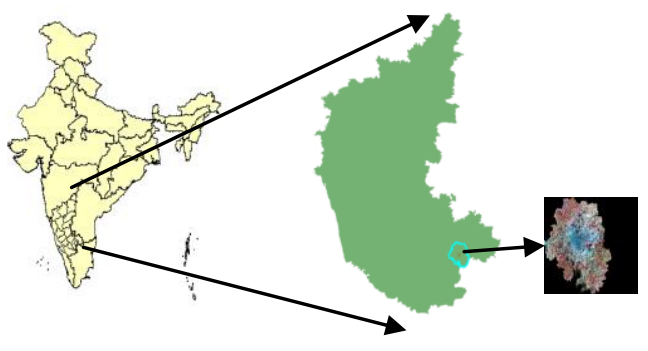

Fig 4: Study of Bangalore urban region is shown.

Bangalore receives moderate rainfall [17]. The mean annual total rainfall is about $880 \mathrm{~mm}$ with 60 rainy days a year over a period of ten years from 2000 to 2010 . The temperature in summer is about $18^{\circ}-38^{\circ}$ and while winter is about $12^{\circ}-25^{\circ}$. Bangalore is located at an attitude of $920 \mathrm{mtrs}$ above the mean sea level. This has created an undulating terrain in the Bangalore region and has facilitated in creation of large number of wetlands. Fig.4 shows study area of Bangalore region.

Maximum likelihood classification is used for classifying the given satellite images which results in thematic images. The thematic images are used to monitor and detect land cover changes in the Bangalore urban region, from the given different satellite images for the years 1973 to 2011. Maximum likelihood classification [16-18] method is applied for all the satellite datasets for digital data exploration. The satellite images are classified to produce four before mentioned thematic classes. The thematic classified images are used 
to analyze the changes that occurred from the year 1973 to 2011. The classification method is applied for data analysis. Table 1 explains the thematic information obtained from the classification technique. Table 2 explains the area coverage for each land cover class by square kilometer percentage across several dates. The resulting thematic land cover change images are shown in Fig.5 - 11. Further, the classification matrix is used to analyze the urban growth. The classified images are interpreted in order to obtain number of pixels for calculating area. Temporal analysis helps in studying the change detection for analyzing decrease in number of water and vegetation image pixels. The results shows that in the years 1973, 1992, and 1999 land cover is slowly increasing in Bangalore district with a total area coverage from $101.80 \mathrm{~km}^{2}$ to $383.93 \mathrm{~km}^{2}$. But a sudden increase in the urban region can be seen during the years 2002 to 2011 from $510.20 \mathrm{~km}^{2}$ to $554.82 \mathrm{~km}^{2}$.

From table 2, it can be seen that during the year 1973, area covered by water is $88.62 \mathrm{~km}^{2}$ and area covered by vegetation is $386.34 \mathrm{~km}^{2}$ while in the year 2011, water is $9.6 \mathrm{~km}^{2}$ and vegetation is $78.31 \mathrm{~km}^{2}$. As a result of urban region development in this region, a drastic increase in urban area is observed between 1973 to 2011. In Fig. 511, different satellite images and classified images are shown. In Fig. 5, it can be seen that built-up area is about $101.1 \mathrm{~km}^{2}$ and in Fig. 11 it is observed that built-up has increased to $1554.8 \mathrm{~km}^{2}$. From table 2, it is seen that water region is decreasing during the year 2002 to 2011 and vegetation region is also following the same pattern. In the year 2002, area covered by vegetation region is $152.65 \mathrm{~km}^{2}$ and where as 2011, area covered by vegetation region is $78.31 \mathrm{~km}^{2}$.

Table 1: Landsat satellite image classification where four different classes built-up, vegetation, water and barren.

\begin{tabular}{|l|l|l|l|l|l|}
\hline $\begin{array}{l}\text { SL } \\
\text { NO }\end{array}$ & YEAR & $\begin{array}{l}\text { Built-up } \\
\text { Pixels }\end{array}$ & $\begin{array}{l}\text { Vegetation } \\
\text { Pixels }\end{array}$ & $\begin{array}{l}\text { Water } \\
\text { Pixels }\end{array}$ & $\begin{array}{l}\text { Barren } \\
\text { Pixels }\end{array}$ \\
\hline 1 & 1973 & 113102 & 429273 & 98472 & 1782995 \\
\hline 2 & 1992 & 338195 & 358549 & 85199 & 1642342 \\
\hline 3 & 1999 & 426590 & 193469 & 30363 & 1773425 \\
\hline 5 & 2002 & 566891 & 169618 & 27139 & 1659567 \\
\hline 6 & 2008 & 595176 & 167752 & 10645 & 1650644 \\
\hline 5 & 2011 & 616475 & 87014 & 10679 & 1710049 \\
\hline
\end{tabular}

Table 2: Converted the Landsat satellite image pixels into $\mathrm{km} 2$ where we can see vegetation and water is decreasing in terms of kilometer.

\begin{tabular}{|l|l|l|l|l|l|}
\hline $\begin{array}{l}\text { SL } \\
\text { NO }\end{array}$ & YEAR & $\begin{array}{l}\text { Built-up } \\
\mathrm{Km}^{2}\end{array}$ & $\begin{array}{l}\text { Vegetation } \\
\mathrm{Km}^{2}\end{array}$ & $\begin{array}{l}\text { Water } \\
\mathrm{Km}^{2}\end{array}$ & $\begin{array}{l}\text { Barren } \\
\mathrm{Km}^{2}\end{array}$ \\
\hline 1 & 1973 & 101.7918 & 386.3457 & 88.6248 & 1604.7 \\
\hline 2 & 1992 & 304.3755 & 322.6941 & 76.6791 & 1478.11 \\
\hline 3 & 1999 & 383.931 & 174.1221 & 27.3267 & 1596.08 \\
\hline 5 & 2005 & 527.1588 & 151.0623 & 9.5976 & 1493.98 \\
\hline 6 & 2008 & 535.6584 & 150.9768 & 9.5805 & 1485.58 \\
\hline 7 & 2011 & 554.8275 & 78.3126 & 9.6111 & 1539.04 \\
\hline
\end{tabular}

For the year 1992, area covered by vegetation land is $14.8 \%\left(322.70 \mathrm{~km}^{2}\right)$ and area covered by water region is $3.48 \%\left(75.9 \mathrm{~km}^{2}\right)$ for the Bangalore region. Urban region has also increased in comparison with the year 1973; it has covered $13.95 \%\left(304.37 \mathrm{~km}^{2}\right)$. Significant increase in urban regions can be noticed for the year 2002, 2005 and 2008 and also sudden decrease in water and vegetation regions. In the year 2011, similar trends were observed. Vegetation land has decreased to $3.6 \%\left(78.31 \mathrm{~km}^{2}\right)$, water region is $0.6 \%\left(9.61 \mathrm{~km}^{2}\right)$ and urban region is $25.40 \%\left(554.8 \mathrm{~km}^{2}\right)$. Here it can be observed from the image, the interpreted results of the vegetation and water regions have decreased drastically. From the year 1973 image, a large number of water bodies can be seen and it has gradually decreased in the year 1992, 1999, 2002, 2005, 2008 and 2011. In Fig.12-15, the four important classes, namely, built-up, water, vegetation and barren land are shown using bar graph. From the graph, we can infer that built-up region has increased which has resulted in a decrease of vegetation and water regions. The results shows that there is sudden increase of land cover change rate between 1973 and 2002. Further it has increased more in 2011 image. The unplanned urbanization has affected the existence of water and vegetation regions further the natural catchments have been affected due to urban growth. This will affect water logging in these regions. From the results, it can be infered that the water regions have disappeared over a period of time due to the human impact.

\section{CONCLUSIONS}

This paper presents the result of Bangalore urban region for over 39 years (1973-2011). In this research, maximum likelihood pattern classification algorithm is 
used in order to analyze temporal satellite images. The results clearly indicated the decrease in number of vegetation image pixels and water image pixels with the increase in number of urban pixels. The year 1973 had a large number of water regions in comparison with 1992 and 2011. As urban regions is growing and it has affected the natural resources like water and vegetation. The influence and impact of human settlements on the environment can be seen and justified.

\section{ACKNOWLEDGEMENT}

This work is supported by the Space Technology Cell, Indian Institute of Science and Indian Space Research Organization grant. Satellite data for experimentation are distributed by the Land Processes Distributed Active Archive Center (LP DAAC), located at the U.S. Geological Survey (USGS) Earth Resources Observation and Science (EROS) Center (lpdaac.usgs.gov).

\begin{tabular}{|l|l|}
\hline Legends & \\
\hline & Built-up Land \\
\hline & Barren Land \\
\hline & Water Land \\
\hline & Vegetation Land \\
\hline
\end{tabular}
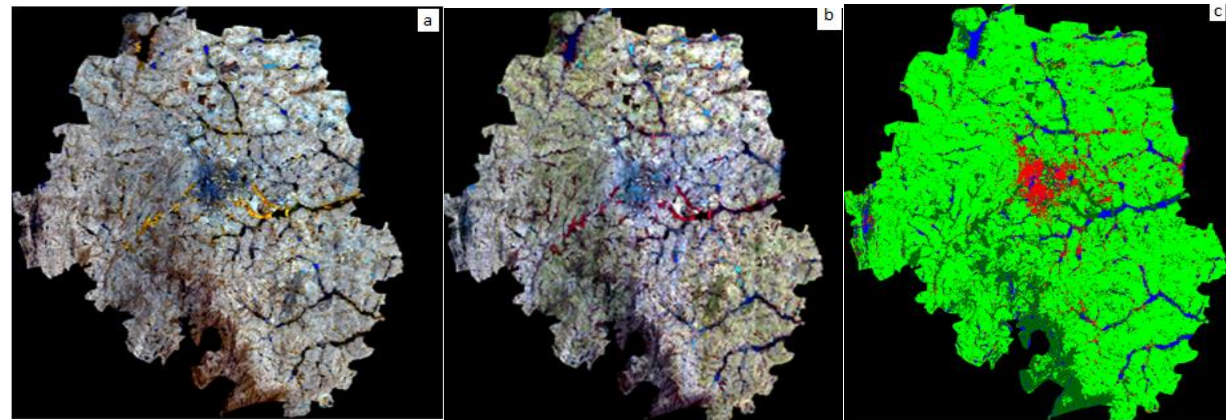

Fig 5: a) TCC b) FCC and c) Classified Landsat MSS 1973 satellite image.
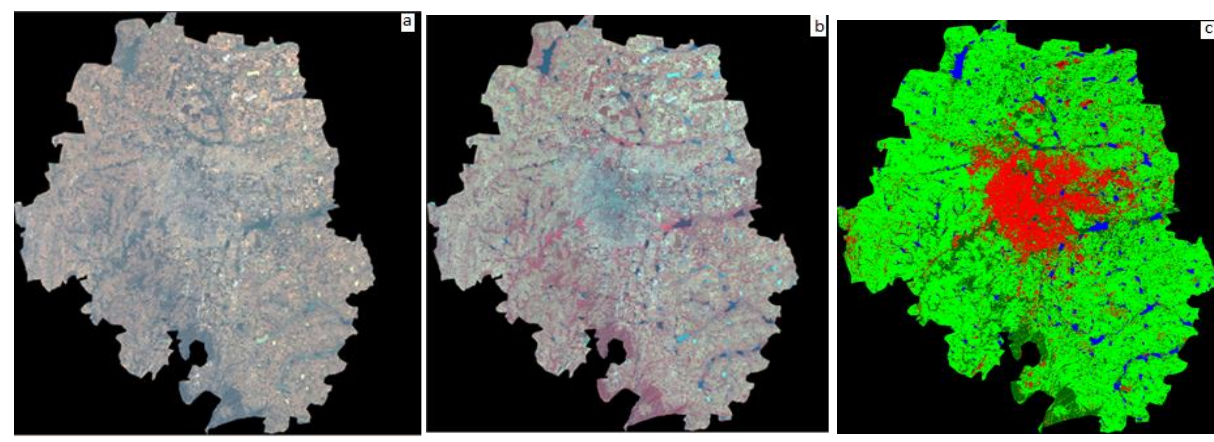

Fig 6: a) TCC b) FCC and c) Classified Landsat TM 1992 satellite image

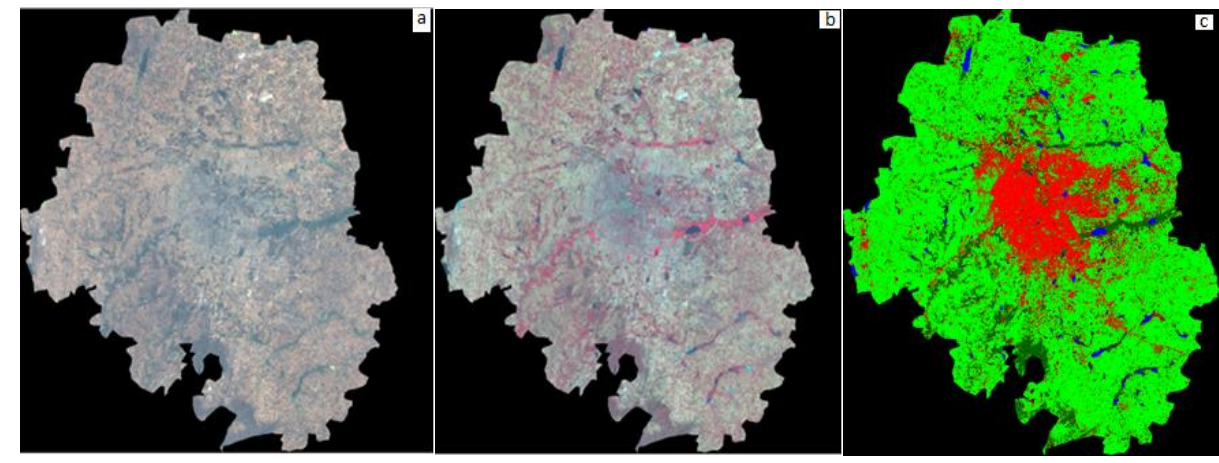

Fig 7: a) TCC b) FCC and c) Classified Landsat 7TM 1999 satellite image. 


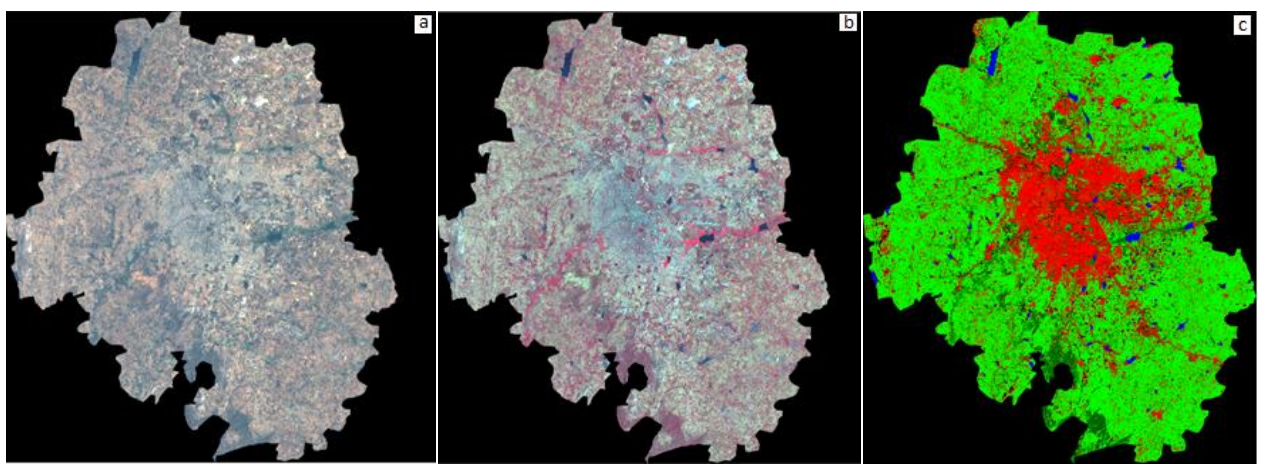

Fig 8: a) TCC b) FCC and c) Classified Landsat ETM+ 2002 satellite image.
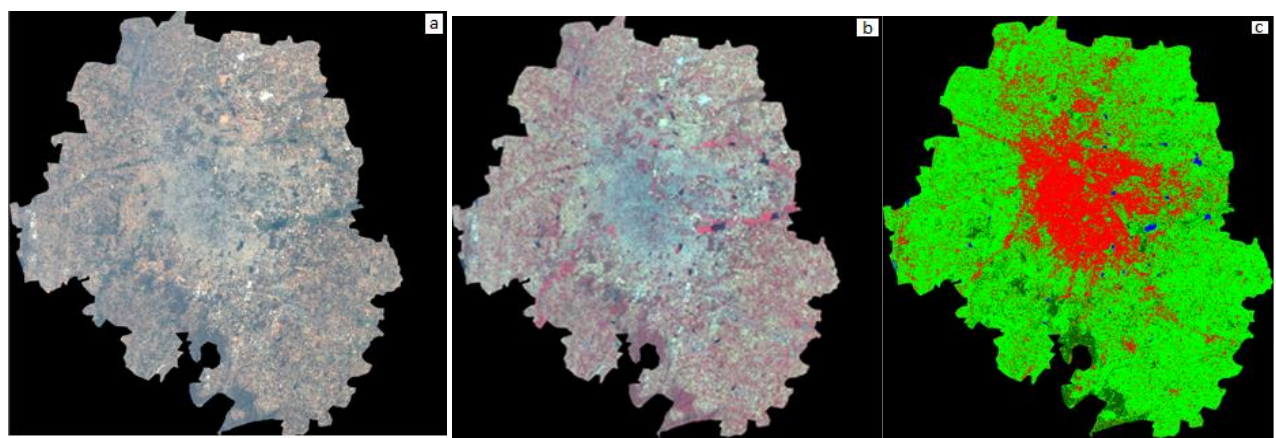

Fig 9: a) TCC b) FCC and c) Classified Landsat ETM+ 2005 satellite image.
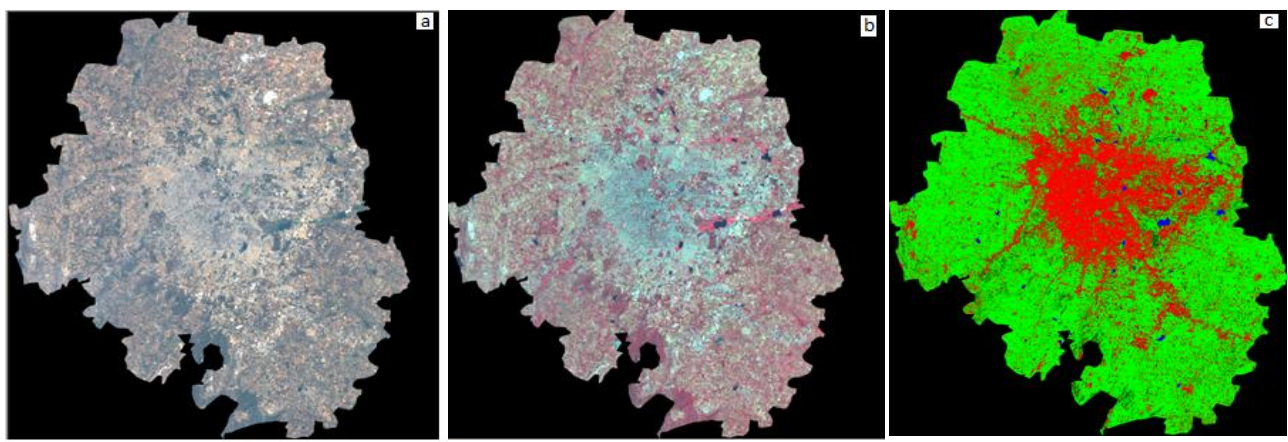

Fig 10: a) TCC b) FCC and c) Classified Landsat ETM+ 2008 satellite image.
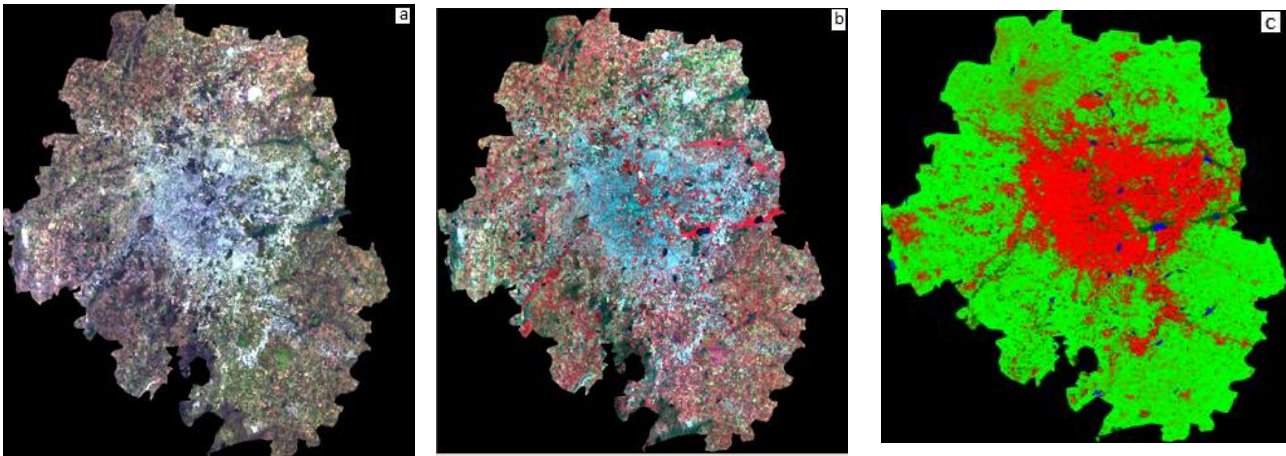

Fig 11: a) TCC b) FCC and c) Classified Landsat ETM+ 2011 satellite image. 


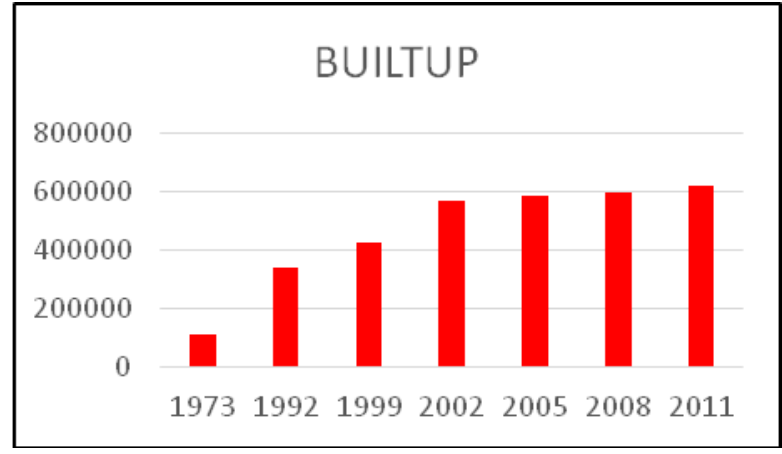

Fig 12: Landsat satellite image classifications results for different year is shown in bar charts for built up region.

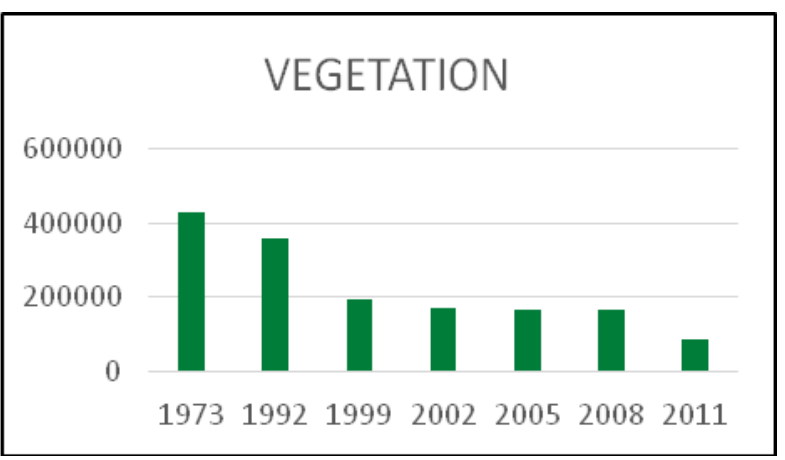

Fig 13: Landsat satellite image classifications results for different year is shown in bar charts for Vegetation region.

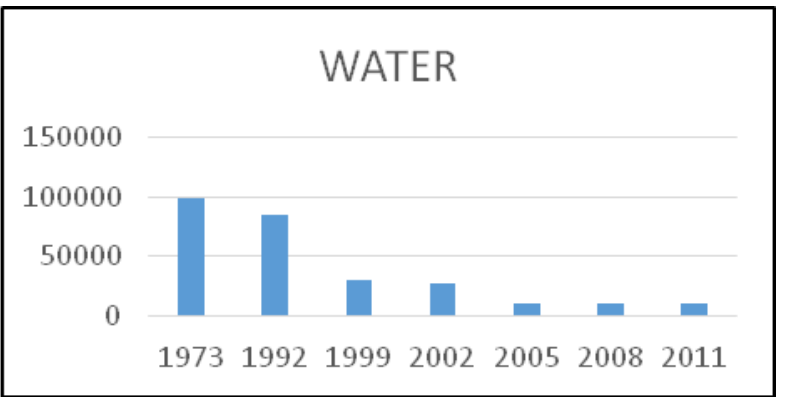

Fig 14: Landsat satellite image classifications results for different years is shown in bar charts for water region.

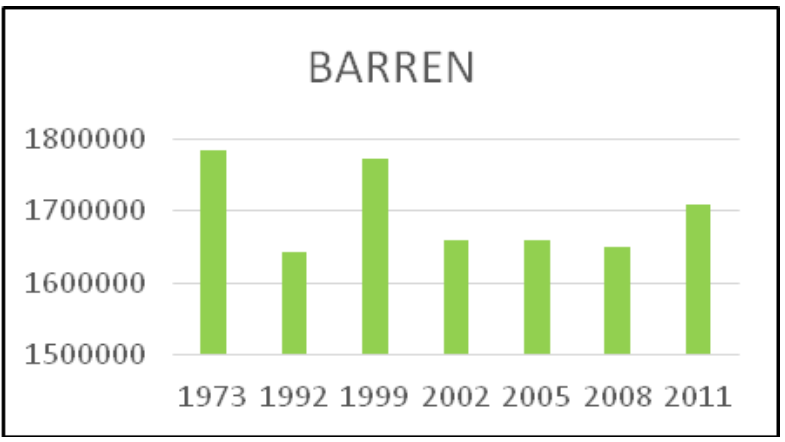

Fig 15: Landsat satellite image classifications results for different years is shown in bar charts for barren land region.

\section{REFERENCES}

[1] Bakr N, Weindorf, D C, Bahnassy, M. H, Marei, S M., \& El-badawi M. M. Monitoring land cover changes in a newly reclaimed area of Egypt using multi-temporal Landsat data, Applied Geography, 30(4), 592-605.Elsevier Ltd. Doi: 10.1016/j.apgeog.2009.10.008.

[2] Ramachandra T. V and Uttam Kumar Wetlands of Greater Bangalore, India: Automatic Delineation through pattern classifiers, Electronic Green Journal, (26), pp-1-22.

[3] Walkey, J. A. Development of a change detection tool for image analysis, MS thesis. University of Wisconsin-Madison, 1997.

[4] Prasad, A. K., Chai, L., Singh, R. P., and Kafatos, M. Crop yield estimation model for Iowa using remote sensing and surface parameters, International Journal of Applied Earth Observation and Geoinformation, 8, 26-33. Doi: 10.1016/j.jag.2005.06.002.

[5] Bhavsar, P. D. Review of remote sensing applications in hydrology and water resources management in India, Advances in Space Research. 4 (11), 193-200, 1984.

[6] Van, W. J. W., Root and R. R. Hyper spectral analysis of multi-temporal Landsat TM data for mapping fuels in Yosemite National Park, Proc. Joint Fire Sci. Conf. and Workshop. Boise, Idaho. June 1999

[7] Zhang, X., Sun, R., Zhang, B. and Tong, Q. Land cover classification of the North China Plain using MODIS EVI time series, ISPRS Journal of Photogrammetry and Remote Sensing. 63, 476-484, 2008.

[8] Verhoest, N., Troch, P. A., De T. F.P. Spatial soil moisture mapping through multi-temporal analysis of ERS-SAR PRI data, 3rd ERS SYMPOSIUM, Florence, 1997.

[9] Ashbindu Singha, Digital change detection techniques using remotely-sensed data, International Journal of Remote Sensing, Volume-10(6), pp 9891003, 1989.

[10] James r. Anderson, Ernest e. hardy, John t. roach, and Richard e. witmer, a land use and land cover classification system for use with remote sensor data, 1972.

[11] El-Kawya, O. R. A., Rod, J. K., Ismail, H. A., and Suliman A. S, Land use and land cover change detection in the western Nile delta of Egypt using remote sensing data, Applied Geography, 31(2), 483-494. Elsevier Ltd. Doi: 10.1016/j.apgeog.2010.10.012.

[12] Dengsheng Lu, Emilio Moran and Scott Hetrick, Detection of impervious surface change with Multitemporal Landsat images in an urban-rural frontier, ISPRS Journal of Photogrammetry and Remote Sensing, 26 Nov 2010.

[13] Robert A. Schowengerdt, Remote Sensing: Models and Methods for Image Processing, third edition.

[14] Gonzalez, R. C. and Woods, R. E, Digital Image Processing, 3E, Prentice Hall, Upper Saddle River, NJ.

[15] Thomas Lille sand, Ralph W. Kiefer and Jonathan Chipman, Remote Sensing and Image Interpretation. 
[16] R. O. Duda,P. E. Hart and D. G. Stork, Pattern Classification 2E John Wiley \& Sons, 2000.

[17] Ramachandra T. V, \& Kumar Uttam, Greater Bangalore: Emerging Urban Heat Island, Urban Ecosystems.

[18] Ethem Alpaydm, Introduction to Machine Learning, MIT Press

[19] Lu, D., \& Weng, Q. (2006), Use of impervious surface in urban land-use classification, Remote Sensing of Environment, 102, 146 - 160. Doi: 10.1016/j.rse.2006.02.010.

[20] Esch, T., Himmler, V., Schorcht, G., Thiel, M., Wehrmann, T., Bachofer, F., Large-area assessment of impervious surface based on integrated analysis of single-date Landsat-7 images and geospatial vector data, Remote Sensing of Environment, 113, 1678-1690. Doi: 10.1016/j.rse.2009.03.012.

[21] Mallick, J., Kant, Y., and Bharath, B. D, Estimation of land surface temperature over Delhi using Landsat-7 ETM +, 12(3), 131-140.

[22] El-Kawya, O. R. A., Rod, J. K., Ismail, H. A., \& Suliman, A. S, Land use and land cover change detection in the western Nile delta of Egypt using remote sensing data, Applied Geography, 31(2), 483-494. Elsevier Ltd. doi: 10.1016/j.apgeog.2010.10.012.

[23] Camps-valls, G., Gómez-chova, L., Munoz-Mari, J., Rojo-álvarez, J. L., Martinez-Ramón, M., (2008), Kernel-Based Framework for Multi-temporal and Multi-source Remote Sensing Data Classification and Change Detection, 46(6), 1822-1835.

[24] Esch, T., Himmler, V., Schorcht, G., Thiel, M., Wehrmann, T., Bachofer, F, Large-area assessment of impervious surface based on integrated analysis of single-date Landsat-7 images and geospatial vector data, Remote Sensing of Environment, 113, 1678-1690. Doi: 10.1016/j.rse.2009.03.012.

[25] Weber, C., and Puissant, A, Urbanization pressure and modeling of urban growth: example of the Tunis Metropolitan Area. Remote Sensing of Environment, 86, 341 - 352. Doi: 10.1016/S00344257(03)00077-4.

[26] Lu, D., Batistella, M., and Moran, E, Multitemporal spectral mixture analysis for Amazonian land-cover change detection Methods, 30(1), pp 87-100.

[27] Avci, M., \& Akyurek, Z, A Hierarchical Classification of Landsat-TM Imagery for Land covers Mapping.

[28] Ramachandra T. V. and Uttam Kumar, Greater Bangalore: Emerging Urban Heat Island, Energy and Wetlands Research Group Centre for Ecological Sciences, Indian Institute of Science, Bangalore 560 012, INDIA, http://www.gisdevelopment.net.

[29] Wang, B., Ono, A., and Muramatsu, K, Automated Detection and Removal of Clouds and their Processing", (2), 453-460.

[30] Tseng, D.-chang, Tseng, H.-ting and Chien, CLiang, Automatic cloud removal from multitemporal SPOT images, Applied Mathematics and
Computation, 205(2), 584-600. Elsevier Inc. doi: 10.1016/j.amc.2008.05.050.

[31] M.J. Pringle,M. Schmidta and J.S. Muira, Geostatistical interpolation of SLC-off Landsat ETM+ images, ISPRS Journal of Photogrammetry and Remote Sensing ,Volume 64(6), pp 654664,2009 .

[32] Gyanesh Chander, Brian L. Markham and Dennis L. Helder, Summary of current radiometric calibration coefficients for Landsat MSS, TM, ETM+, and EO1 ALI sensors, Remote Sensing of Environment, Volume 113(5), pp 893-903.

[33] Song, C., Woodcock, C. E., Seto, K. C., Lenney, M. P., and Macomber, S. A, Classification and Change Detection Using Landsat TM Data: When and How to Correct Atmospheric Effects? Data Processing, 4257(00).

[34] Kang-tsung Chang, Introduction to Geographic Information Systems.

[35] S. N. Omkar, J. Senthilnath, Dheevatsa Mudigere and M. Manoj Kumar, Crop Classification using Biologically-inspired Techniques with High Resolution Satellite Image, Journal of the Indian Society of Remote Sensing Volume 36(2), 175-182.

[36] Adel Shalaby and Ryutaro Tateishi, Remote sensing and GIS for mapping and monitoring land cover and land-use changes in the Northwestern coastal zone of Egypt, Applied Geography, Volume 27(1), and Pages 28-41, 2007.

[37] Peter Potapov, Svetlana Turubanova, and Matthew C. Hansen, Regional- Scale boreal forest cover and change mapping using Landsat data composites for European Russia, Remote Sensing of Environment, October 2010.

[38] Hugo Carrão, Paulo Gonçalves and Mário Caetano, Contribution of multispectral and Multitemporal information from MODIS images to land cover classification, Remote Sensing of Environment, Volume 112(3), PP 986-997, 2008.

[39] David P. Roy, Junchang Ju, Philip Lewis, Crystal Schaaf, Feng Gao, Matt Hansen and Erik Lindquist, Multi-temporal MODIS-Landsat data fusion for relative radiometric normalization, gap filling, and prediction of Landsat data, Remote Sensing of Environment, Volume 112, Issue 6(16) Pages 3112$3130,2008$.

[40] J. Senthilnath, S.N. Omkar, V. Mani and T. Karthikeyan, Multi-objective Discrete Particle Swam Optimization for Multi-sensor Image Alignment" IEEE Geoscience and Remote Sensing Letters (GRSL), Vol. 10(5), pp. 1095 - 1099, 2013.

[41] J.Senthilnath, S.N. Omkar, V. Mani, Naveen P Kalro and P.G. Diwakar, Multi-objective genetic algorithm for efficient point matching in multisensor satellite image" Proc. IEEE International Geoscience and Remote Sensing Symposium (IGARSS'12), Munich, Germany, 2012.

[42] J.Senthilnath, S.N. Omkar, V. Mani and T. Karthikeyan, Multi-objective optimization of 
satellite image registration using discrete particle swarm optimisation Proc. IEEE INDICON'11, Hyderabad, India, 2011.

[43] J. Senthilnath, Shivesh Bajpai, S.N. Omkar, P.G. Diwakar and V. Mani An approach to Multitemporal MODIS Image analysis using Image classification and segmentation, Advances in Space Research, Vol. 50(9), pp. 1274 - 1287, 2012.

[44] C.S. Arvind, Ashoka Vanjare, S.N. Omkar, J. Senthilnath, V. Mani and P.G. Diwakar, Multitemporal Satellite Image Analysis Using Unsupervised Techniques, Advances in Computing and Information Technology, (Eds. N. Meghanathan et al.) Advances in Intelligent Systems and Computing, Springer Verlag, Berlin, Germany, vol. 177 , pp. $757-765,2013$.

[45] J. Senthilnath, Vikram Shenoy H, Ritwik Rajendra, S.N. Omkar, V. Mani and P.G. Diwakar, Integration of speckle de-noising and image segmentation using Synthetic Aperture Radar image for flood extent extraction, Journal of Earth System Science, (Springer-Verlag), Vol. 122(3), pp. 559 - 572, 2013.

[46] J. Senthilnath, S.N. Omkar, V. Mani, Nitin Karnwal and Shreyas P.B, Crop Stage Classification of Hyperspectral Data using Unsupervised Techniques IEEE Journal of Selected Topics in Applied Earth Observations and Remote Sensing (IJSTARS), Vol. 6(2), pp. 861 - 866, 2013.

[47] J. Senthilnath, S.N. Omkar, V. Mani and P.G. Diwakar, Multi-temporal Satellite Imagery for Flood Damage Assessment, Journal of the Indian Institute of Science, Special Issue on imaging and microscopy, Vol. 93(1), pp. 105 - 116, 2013.

[48] J. Senthilnath, S.N. Omkar, V. Mani, Tejovanth N, P.G. Diwakar and Archana Shenoy B, Hierarchical Clustering Algorithm for Land Cover Mapping using Satellite Images, IEEE Journal of Selected Topics in Applied Earth Observations and Remote Sensing, Vol. 5(3), pp. 762 - 768, 2012.

[49] J. Senthilnath, S.N. Omkar and V. Mani, Clustering using firefly algorithm: performance study Swarm and Evolutionary Computation, Vol. 1(3), pp.164 $171,2011$.

[50] S.N. Omkar, Sivaranjani V, J. Senthilnath and Suman Mukherjee, Dimensionality Reduction and Classification of Hyperspectral Data, International Journal of Aerospace Innovations, Vol. 2(3), pp. $157-163,2010$.

[51] J. Senthilnath, M. Rajeswari and S.N. Omkar, Automatic Road Extraction using High Resolution Satellite Image based on Texture Progressive Analysis and Normalized Cut method, Journal of the Indian Society of Remote Sensing, (SpringerVerlag), Vol. 37(3), pp. 351 - 361, 2009.

[52] S.N. Omkar, J. Senthilnath, Dheevatsa Mudigere and Manoj Kumar M, Crop Classification using Biologically Inspired Techniques with High Resolution Satellite Image, Journal of the Indian Society of Remote Sensing (Springer-Verlag), Vol. 36(2), pp. 172 - 182, 2008.
[53] J. Senthilnath, Ankur raj, S.N. Omkar, V. Mani and Deepak kumar, Quasi-Based Hierarchical Clustering for Land Cover Mapping Using Satellite Images, Proceedings of Seventh International Conference on Bio-Inspired Computing: Theories and Application Advances in Intelligent Systems and Computing, Springer India, Vol. 202, pp. 53 - 64, 2013.

[54] J. Senthilnath, Vikram Shenoy H, S.N. Omkar and V. Mani, Spectral-spatial MODIS image analysis using Swarm intelligence algorithms and region based segmentation for flood assessment, Proceedings of Seventh International Conference on Bio-Inspired Computing: Theories and Application (Eds. J.C. Bansal et al.) Advances in Intelligent Systems and Computing, Springer India, Vol. 202, pp. 163 - 174, 2013.

[55] J. Senthilnath, Vipul Das, S.N. Omkar and V. Mani, Clustering using Levy Flight Cuckoo Search Proceedings of Seventh International Conference on Bio-Inspired Computing: Theories and Application (Eds. J.C. Bansal et al.) Advances in Intelligent Systems and Computing, Springer India, Vol. 202, pp. $65-75,2013$.

[56] J. Senthilnath, Shreyas P.B, Ritwik Rajendra, S.N. Omkar, V. Mani and P.G. Diwakar, Multi-Sensor Satellite Image Analysis using Niche Genetic Algorithm for Flood Assessment, Swarm, Evolutionary and Memtic Computing Conference, Springer-Verlag Berlin Heidelberg, LNCS 7677, pp. 49 - 56, Springer, Heidelberg, 2012.

[57] J. Senthilnath, S.N. Omkar, V. Mani and Nitin Karnwal, Hierarchical artificial immune system for crop stage classification, Proc. IEEE INDICON'11, Hyderabad, India, 2011.

[58] J. Senthilnath, S.N. Omkar, V. Mani, Tejovanth N, P.G. Diwakar and Archana Shenoy B, MultiSpectral Satellite Image Classification using Glowworm Swarm Optimization, Proc. IEEE International Geoscience and Remote Sensing Symposium (IGARSS'11), Vancouver, Canada, 2011.

[59] M. Rajeswari, K.S. Gurumurthy, S.N. Omkar, J. Senthilnath and L. Pratap Reddy, Automatic Road Extraction using High Resolution Satellite Images based on Level Set and Mean Shift Methods, Proc. IEEE 3rd International Conference on Electronics Computer Technology (ICECT'11), Kanyakumari, India, 2011.

\section{AUTHORS}

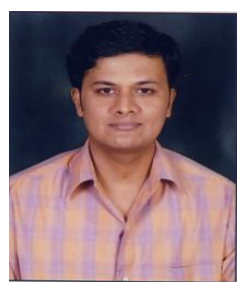

Mr. Ashoka Vanjare, male is a project assistant at Indian institute of science, Bangalore. $\mathrm{He}$ is currently working in the field of remote sensing and Geographic information system. His research interests include computer vision, digital image 
processing and Software Development.

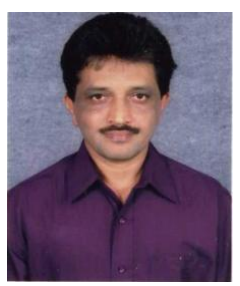

Dr S N Omkar, male, is the principal research scientist at Indian institute of science, Bangalore. He is currently working in the field of neural networks, unmanned aerial vehicles, bio-mechanics, remote sensing and Geographic information system.

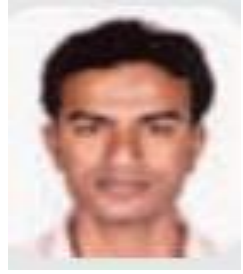

Mr. J Senthilnath, male, is a research scholar at Indian institute of science, Bangalore. $\mathrm{He}$ is currently working in the field of remote sensing and Geographic information system. His research interests include computer vision, digital image processing.

How to cite this paper: Ashoka Vanjare, S.N. Omkar, J.Senthilnath,"Satellite Image Processing for Land Use and Land Cover Mapping", IJIGSP, vol.6, no.10, pp.18-28, 2014.DOI: 10.5815/ijigsp.2014.10.03 